\title{
Drunken drive detection with smart ignition lock
}

\author{
S. L. A. Muthukarpan ${ }^{1}$, M. N. Osman ${ }^{2}$, M. Jusoh ${ }^{3}$, T. Sabapathy ${ }^{4}$, \\ M. K. A. Rahim ${ }^{5}$, M. Elshaikh ${ }^{6}$, Z. I. A. Khalib ${ }^{7}$ \\ ${ }_{1,2,3,4,6,7}$ Bioelectromagnetics Research Group (BioEM), School of Computer and Communication Engineering, \\ University Malaysia Perlis, Pauh Putra Main Campus, Malaysia \\ ${ }^{5}$ School of Electrical Engineering, Faculty of Engineering, University Technology Malaysia, Johor, Malaysia
}

\begin{tabular}{l} 
Article Info \\
\hline Article history: \\
Received Jan 3, \\
Revised Mar 8, \\
Accepted May 7, \\
\hline Keywords: \\
Alert system \\
Drunk detection \\
GSM \\
Ignition lock
\end{tabular}

\begin{abstract}
Drink and drive issue have become solemnly that needs immediate attention. This is due to drivers' ignorance towards road rules and regulations and their selfish attitude that caused loss of innocent lives. Although previously there is a drunk detecting mechanism using breathalyzer but it isn't suitable for current fast-paced lifestyle. Therefore, to overcome these issues, this system is proposed. This system is fixed on vehicle's steering to measure alcohol concentration reading using MQ-3 sensor from the driver's exhaled breath. If the driver found to be drunk beyond the threshold level of $400 \mathrm{ppm}$, then ignition lock is activated and the car engine does not start till alcohol concentration falls to a safe level. Or, if the driver consumes an alcoholic drink while driving, upon exceeding permissible limit, the car slows down till it stops. Then, the location of the vehicle is tracked and sent as Google Map integrated link via text message to authorized unit. Simultaneously, the car buzzer goes off while the car slows down so that surrounding road users are aware of the driver's condition and drives at a distance. The proposed detection system is highly potential to be implemented for reducing the drunk and drive accidents.
\end{abstract}

This is an open access article under the CC BY-SA license.

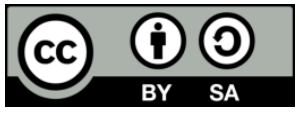

\section{Corresponding Author:}

M. N. Osman,

School of Computer and Communication Engineering,

University Malaysia Perlis,

02600 Arau Perlis, Malaysia.

Email: nasrun@unimap.edu.my

\section{INTRODUCTION}

Currently reported by the World Health Organization (WHO), Malaysia lies at number 59 among 183 countries worldwide for road traffic accidents, stands with a percentage of 24.51 death rates by both male and female due to road accidents; stands medium high level. Apparently, death rates on Malaysian roads is third highest globally, more than China and India reads the headline of an article [1]. This data is consistent with the data as provided by Malaysian Institute Road Safety Research (MIROS), whereby, among eight common causes of a vehicle accident in Malaysia, drunk and driving cases is the second in the list and second highest in the world with highest amount of lives lost. According to MIROS report in year 2012 [2], $23.3 \%$ contribute to drunk and driving whereby 13 times more likely to cause an accident. Based on these statistics motivates the needs to reduce and prevent such road accidents.

The old-fashioned method used by officers to detect alcohol in the driver is by using Breathalyzer. Even though it has proved its function, however this method is not efficient. Nevertheless, it is impossible to do road block all the time and check driver of each car using Breathalyzer [3]. Breathalyzer is a device to check alcohol presence in the driver's breath by making them blow into it. This method is not as practical as it can cause congestion and traffic during peak days. In addition, there are chances of the driver to bribe 
officers just to avoid being summoned. If they escape this road block, and continue to drive in a drunken state, they are risking every other road users.

This project has overcome previous paper limitations as a part and parcel of the system. As proposed in $[4,5]$, the system uses MQ-2 sensors to detect the presence of alcohol in the driver's breath. MQ-2 is designed to test for combustible gases such as LPG [6]. It can be tested for alcohol too, but MQ-3 sensor [7] is specially made to test for alcohol vapor in which it has a more accurate reading and higher sensitivity than MQ-2. Then, another method that was used to detect presence of alcohol is from driver's sweat using the IR sensor [8] whereby neither using the air-conditioner nor opening the window will crash the system functionality totally. And besides, every human's perspiration rate differs when consuming alcohol. A lack of accuracy will lead to poor or no result of the presence of alcohol in driver's sweat.

Other than that, one of the paper has used mobile phone [9] which has an accelerometer and an orientation sensor whereby the mobile phone computes accelerations based on sensor readings and compares it with typical drunk driving patterns extracted from real driving tests through acceleration of vehicles related to lane position maintenance problems such as weaving, drifting, swerving, turning abruptly or with a wide radius and speed control problems like accelerating or decelerating suddenly, braking erratically and stopping abruptly. The loophole in this system is that if kids' play with this phone or it gets damaged due to fall as it is portable, then the system fails.

In spite of that, paper [10] made a system that has only alert system to prevent car theft by having password access, but it can be further enhanced by having an alcohol detection as well. Although the paper achieved its objective, but with alcohol detection the functionality of the system will be enhanced as well as reduce drunk and drive cases on the road. Furthermore, in [11], the system has everything except for buzzer and led. It might seem that this paper lacks of something minor, but it does make some effect on the system. As such, while on the road, if the driver is consuming alcohol and it is within the range, any moment, it can go over the threshold level. Led light is the indicator for the driver's soberness in a car which can be seen by others road vehicle, and buzzer is necessary to alert any road user that the driver is not conscious enough to drive his vehicle. So, lack of this does make a little impact which can cost a life.

Whilst in [12], there is no tracking system or any alert system except alcohol detection, which is not enough to take any further action. Although, the car does not start up upon detecting alcohol in the driver's breath, this system was not tested for the condition whereby a driver gets drunk while driving. And another important point would be the system was tested with butane from lighter than ethanol. In [13], the paper only detects alcohol presence and locks the car upon hitting threshold level but no alert system to inform authorities. Not forgetting in paper [14], the system only detects alcohol presence and rings an alarm, but lacks GSM and GPS which is more important to alert the next of kin. Another paper had used GPS only, excluding GSM [15] which will only detect the location of the vehicle, but will not alert next of kin or police office for further action.

Yet, a paper was vice versa whereby it has GSM instead of GPS [16] whereby the police cannot trace the car location and either help the driver or take legal action. Apart from that in [17-19], the system only has buzzer as an alarm system which is insufficient as it lacks of tracking system and presence of alarm inside the car can cause panic attacks and worsen the situation. Next, in [20-22] the proposed system does not have a GPS tracker or a GSM module that can track the location of the vehicle and notify authorized people via SMS. This limitation can only detect alcohol presence in the driver's breath and stops the engine from running, but he will not be prosecuted for his irresponsible act of driving dangerously.

Thus, the solution for this is by creating this system with engine lock using GSM, which is embedded into every four wheel vehicle. This system automatically detects the driver's intoxication level using an alcohol sensor (MQ-3 sensor). By using ignition, the engines lock if the driver is found to have exceeded the threshold limit of alcohol upon starting the car or slow down a moving car in case the driver consumes alcohol while driving. This system analyses alcohol consumption by a vehicle driver and alerts authorized person if the driver is drunk by sending the vehicle's location using GPS module. Hence, this system can reduce drunken driving accidents and alert other vehicle users besides alerting officers so legal actions can be taken.

\section{RESEARCH METHOD}

Figure 1 shows the block diagram of the proposed system. Microcontroller used in this project is ATMEGA 2560 of Arduino Mega board [23]. All the components are embedded to this microcontroller. Alcohol sensor, MQ-3 is the input to the microcontroller because it detects the presence of alcohol in the driver's breath and sends data to the microcontroller for the further action. As seen from the block diagram, LED, LCD, Buzzer, DC motor, Ignition lock are connected to an output from the microcontroller.

The flowcharts for overall system, GPS tracker [24] and GSM module [25] are shown in Figure 2. Figure 2(a) describes flowchart of overall system. When the system is started, alcohol sensor is activated by the car engine. It will measure the presence of alcohol in the driver's breath and display his condition in 
LCD. Upon reaching the decision box, if the driver is found to be intoxicated by alcohol sensor, engine runs low and ignition shuts down. Next, alarm rings continuously to alert other vehicle user on the road. Then, the location of the vehicle is tracked down and the details are sent to officers and next of kin via SMS notification else the vehicle location is continued to be traced till its accurate position is located.

Figure 2(b) is the flowchart for GPS tracker and GSM module. When alcohol value exceeds threshold level, an alarm rings continuously first. Then, data are sent to GPS tracker. This module the track position of the vehicle and sends the details back to the microcontroller. From there, GSM module is activated. A SMS notification will be sent to officers and next of kin to alert driver's condition and vehicle current location. Those are preregistered numbers which are saved on the SIM card of GSM module. The process ends once the respective people receive text and are able to track down the vehicle.

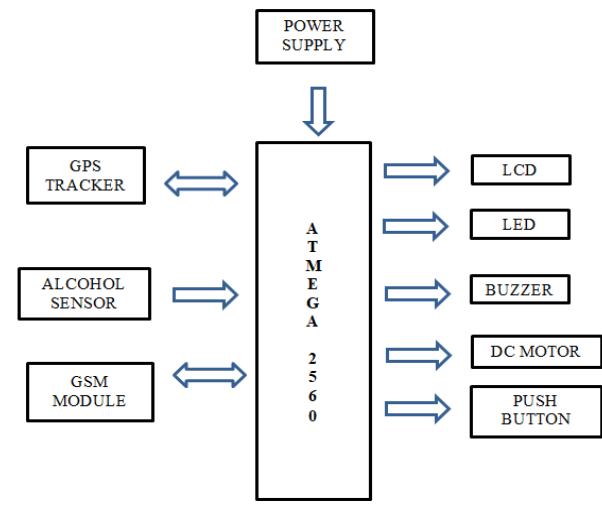

Figure 1. Block diagram of system

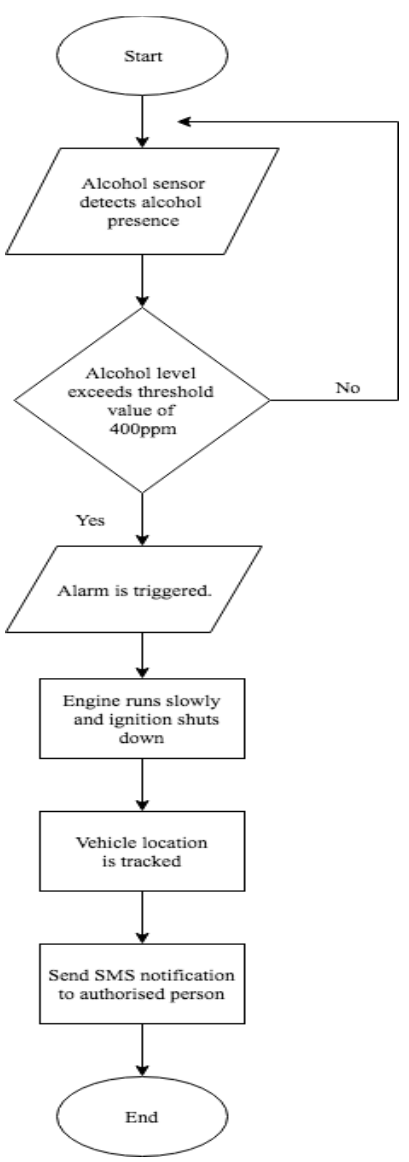

(a)
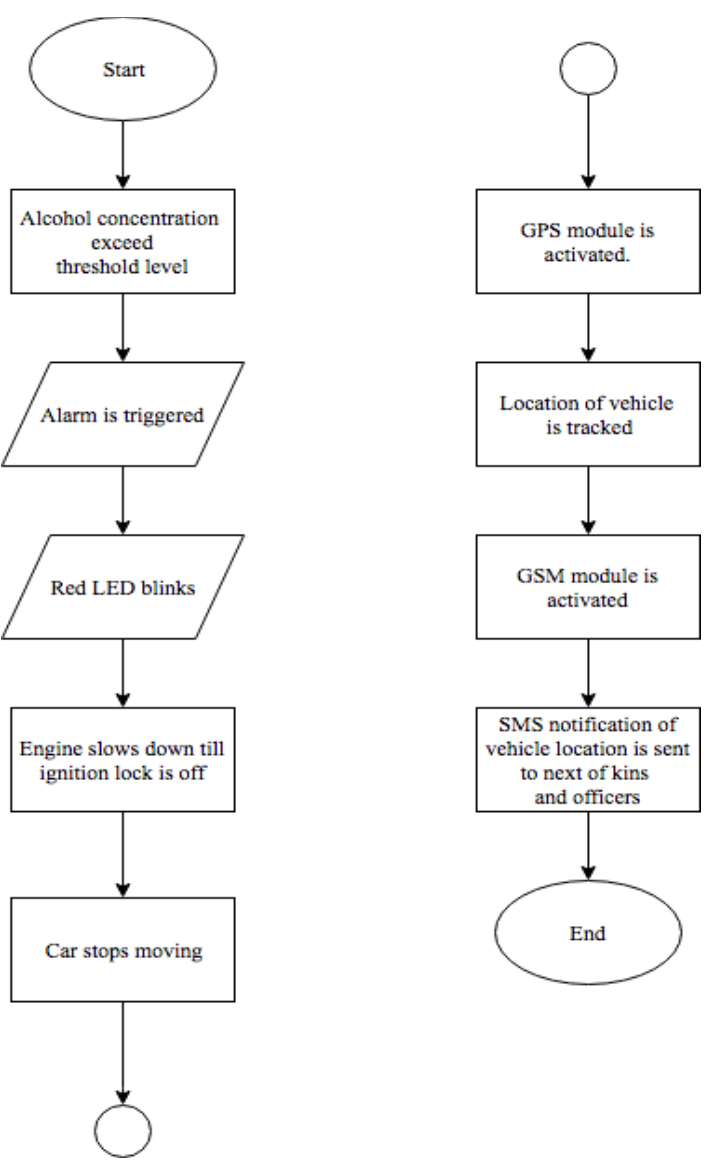

(b)

Figure 2. Flowchart of, (a) Overall system, (b) GPS and GSM 
Figure 3 shows a flowchart process of alcohol sensor in this project. Firstly, alcohol sensor detects alcohol presence in the driver's breath. If the alcohol value is less than $200 \mathrm{ppm}(0.4 \mathrm{mg} / 100 \mathrm{ml})$, then the alarm is off, ignition is on and green light blink indicating safe. "You are sober", "Safe to drive" message will be displayed on LCD. Next, if the alcohol value is more than or equal to 200ppm and less than $400 \mathrm{ppm}(0.8 \mathrm{mg} / 100 \mathrm{ml})$ then, the alarm triggers every 10 second, ignition is still on and yellow light blinks indicating less danger. "You are drunk", "Drive safe" message will be displayed on LCD.

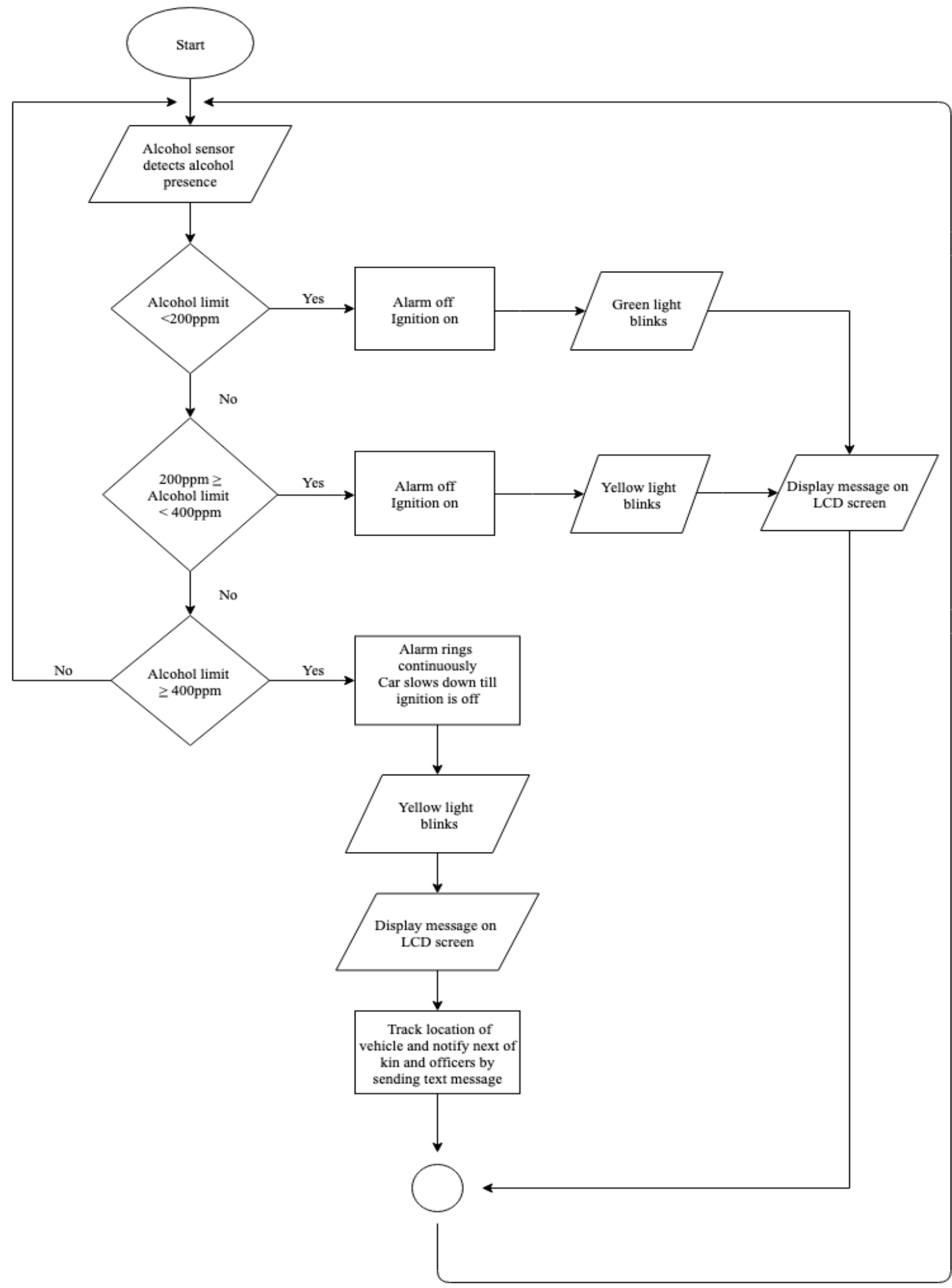

Figure 3. Flowchart of alcohol sensor 
If the alcohol value is more than or equal to $400 \mathrm{ppm}$, then alarm goes off completely, the engine slows down and ignition turns off. The red light will blink which indicates danger. "You are drunk", "Stop driving" message will be displayed on the LCD screen. This message is to alert driver on his condition so that he will be careful on the road whilst both alarm and led light is to alert surrounding vehicle users. When the alcohol sensor detects the high amount of alcohol in the driver's breath than the vehicle location is tracked down and is sent via SMS notification to both officers and next of kin.

Once the entire system functions accordingly, it is then tested by developing a prototype, as shown in Figure 4. Figure 4(a) shows entire connection of the system before being embedded into a prototype. As seen in this figure, there is a connection of the Arduino MEGA 2560 which interfaces with alcohol sensor, MQ-3, 16X2 LCD, buzzer, LED, GPS and GSM module with DC motors. The complete prototype is shown in Figure 4(b).

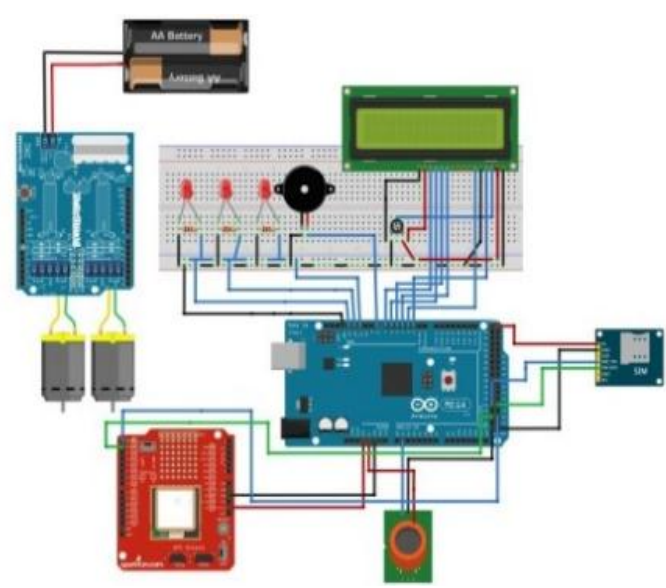

(a)

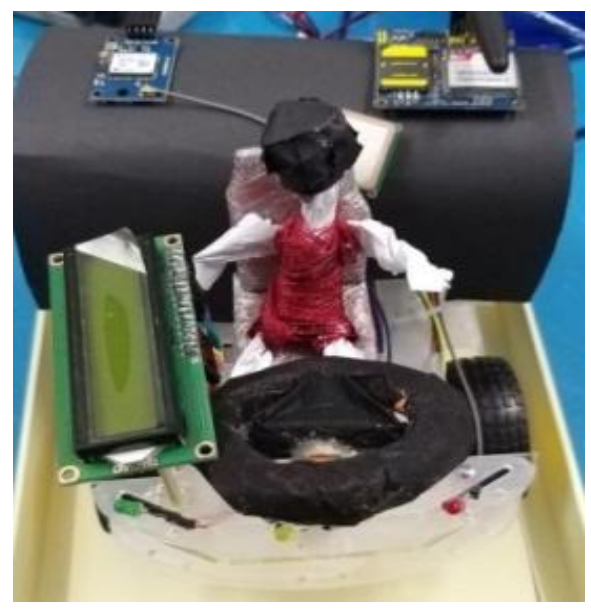

(b)

Figure 4. Connection of components to, (a) Arduino board, (b) Dummy car prototype

\section{RESULTS AND DISCUSSION}

\subsection{Displaying text on liquid crystal display (LCD)}

Once the hardware is completed, the system is powered by using $5 \mathrm{~V}$ power supply. Then, the potentiometer is adjusted to display the characters accordingly. Right then, start up code is uploaded using Arduino Ide into the main board. Then, LCD screen displays the word "WELCOME" in the first line and "SAFE JOURNEY" in the second line. The output display is shown in Figure 5(a). When the alcohol value measured is less than $200 \mathrm{ppm}$, the LCD displays "You are sober", in the first line and "Safe to drive", at the second line. This is shown in Figure 5(b). Next, when alcohol is in the range between 200 ppm and 400 ppm, the LCD displays "You are drunk", in the first line and "Drive Safe", at second line which is shown in Figure 5(c). Upon exceeding the threshold limit of 400 ppm, LCD screen displays "YOU ARE DRUNK", in the first line and "STOP DRIVING", at the second line as shown in Figure 5(d).

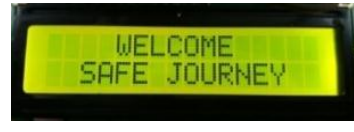

(a)

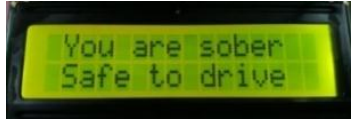

(b)

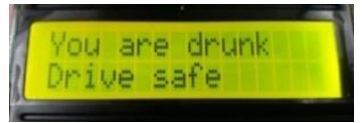

(c)

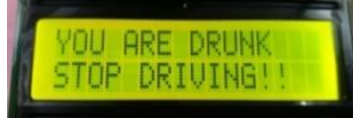

(d)

Figure 5. LCD display during, (a) System start up, (b) Sober, (c) Mildly drunk, and (d) Drunk

\subsection{LED blinking}

As per the condition set in this system, three different color LED is added to the hardware that acts as an emergency light indicator. The yellow LED will blink when alcohol limit is less than 200 ppm right after the text is displayed for it. This goes same for the next condition of alcohol limit is within the range of $200 \mathrm{ppm}$ and $400 \mathrm{ppm}$ which is indicated by a green light and upon exceeding the threshold 
value, red LED blinks which is followed by an alarm which rings continuously till alcohol falls back below that limit. Both Figures 6(a)-(b) shows LED blinking for first two conditions of alcohol detection. Since buzzer functionality cannot be shown through sound recording, a picture of LED red blinking for the third condition is shown instead in Figure 6(c).

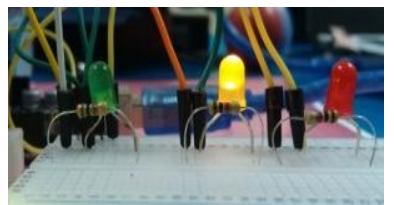

(a)

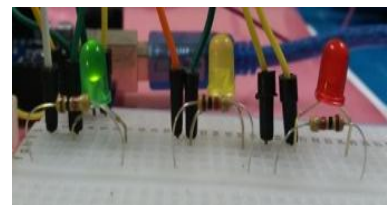

(b)

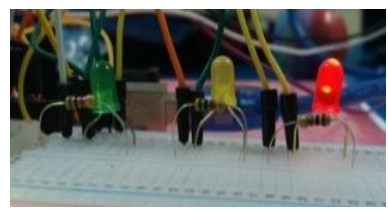

(c)

Figure 6. LED Blinking, (a) Yellow LED, (b) Green LED and (c) Red LED

\subsection{Interfacing GSM and GPS module with Arduino MEGA}

Before interfacing GPS location to GSM module to send text messages to the person in-charge, both the modules are tested separately for its functionality. For GPS module (GY-NEO6MV2), latitude and longitude were recorded live and is displayed in serial monitor. Then, for GSM module, a reloaded SIM card is placed in the module, which will send a text message to respective person upon obtaining the location of drunk drivers. Upon integrating both these modules, the location of the drunk driver vehicle which is sent via text message is shown in Figure 7(a) together with Google map location of the coordinates (b).

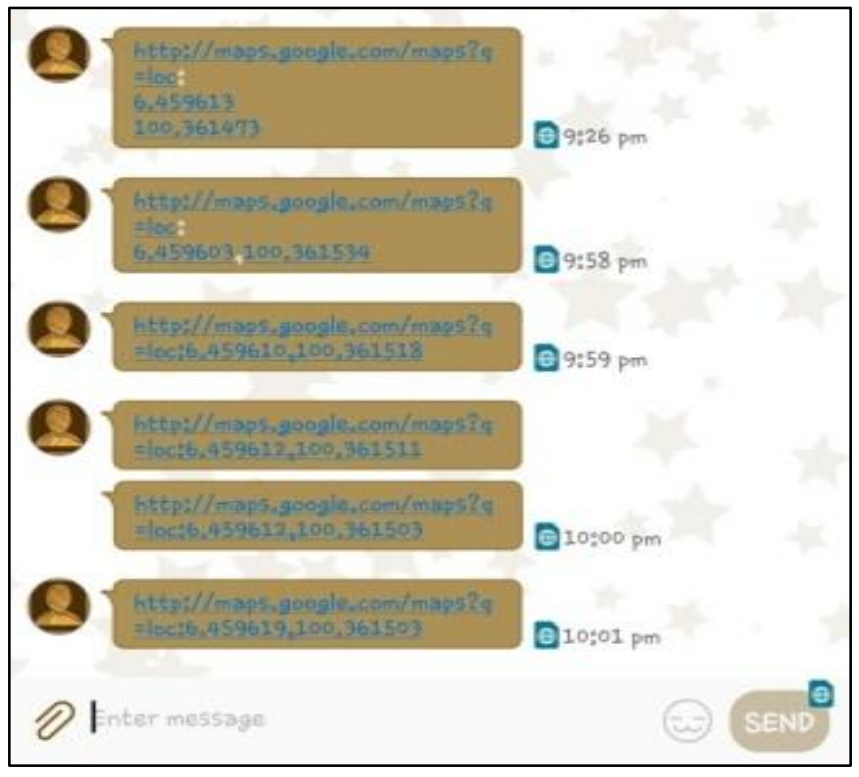

(a)

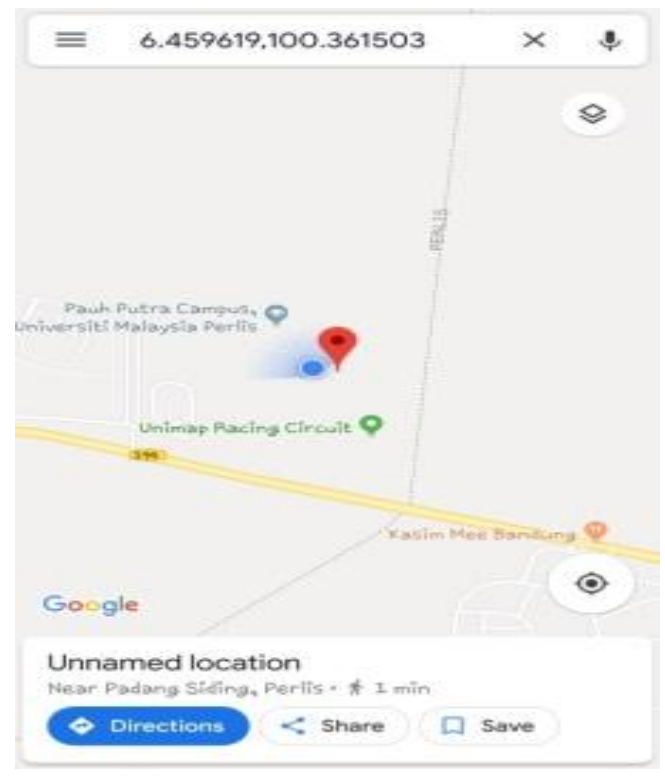

(b)

Figure 7. Result of GSM module, (a) Text message screenshot of driver's location, (b) Google map integration

\section{CONCLUSION}

Drunken driving and alcohol detection with alert system have successfully been completed as per requirements. The system runs perfectly in detecting the presence of alcohol in the driver's breath that does a further action which is tracking the location of the car and sending its position in latitude and longitude via text message to authorized persons. This system is then fixed in a car prototype which shows how it works if implemented in the car. This system can be further modified for better improvement in future. The limitation can be overcome by using more precise and advanced software to be implemented in the steering. In addition, the reading should not influence by the presence of perfume or air freshener. A secondary sensor can be added so that it will support the functionality of alcohol sensor and will give 
an accurate output and a system that provides more useful details about the accident vehicle other than the location and driver's condition. Besides that, rather than sending text messages to authority, it is best to send the location to a system base or web server. As such a cloud base data must be created so that it is easier for authorized person to trace the location of car for monitoring purposes.

\section{ACKNOWLEDGEMENTS}

The author thanks University Malaysia Perlis, University Technology Malaysia, University Technical Malaysia Melaka, University Tun Hussein Onn Malaysia and Research Management and Innovation Centre for the support of the research work under collaborative research grant 9023-00003.

\section{REFERENCES}

[1] T. Ruxyn and J. Clrek Maxwell, "Death rates on Malaysian roads is 3rd highest globally, more than China and India," SAYS NEWS, vol. 2, pp. 68-73, 2017.

[2] N. Mohamed, W. A. Batcha, N. K. Abdullah, M. F. Mohd Yusoff, S. A. Syed Mohamed Rahim, and M. S. Mahmood, "Alcohol and drug use among fatally injured drivers in urban area of Kuala Lumpur," Malaysian Institute of Road Safety Research, pp. 1-45, 2012.

[3] H. A. Rahim and S. D. S. Hassan, "Breathalyzer enabled ignition switch system," 2010 6th International Colloquium on Signal Processing \& its Applications, pp. 1-4, 2010.

[4] Prashanth K. P., K. Padiyar, Naveen Kumar. P. H, and K. S. Kumar, "Road accident avoiding system using drunken sensing technique," International Journal of Engineering Research \& Technology, vol. 3, no. 10, pp. 818-823, 2014.

[5] M. Vaishnavi, V. Umadevi, M. Vinothini, Y. Bhaskar Rao, and S. Pavithra, "Intelligent alcohol detection system for car," International Journal of Scientific \& Engineering Research, vol. 5, no. 11, pp. 598-601, 2014.

[6] T. Data, "MQ-2 semiconductor sensor for combustible gas," Pololu, pp. 1-2, 2016.

[7] Zhengzhou, "Alcohol gas sensor," Sparkfun, pp. 1-21, 2014. [Online]. Available at: https://cdn.sparkfun.com/datasheets/Sensors/Biometric/MQ-3\%20ver1.3\%20-\%20Manual.pdf.

[8] S. Aravind, T. Karthick, and U. Sakthivel, "E-Eyanthra perspiration based drunken driving prevention system," 4th International Conference on New Trends in Information Science and Service Science, pp. 270-274, 2010.

[9] J. Dai, J. Teng, X. Bai, Z. Shen, and D. Xuan, "Mobile phone based drunk driving detection," 20104 th International Conference on Pervasive Computing Technologies for Healthcare, pp. 1-8, 2010.

[10] A. Omanakuttan, D. Sreedhar, A. Manoj, A. Achankunju, and C. M. Cherian, "GPS and GSM based engine locking system using smart password," Int. Journal of Computer Sciences and Engineering, vol. 5, no. 4, pp. 57-61, 2017.

[11] P. Sahu, S. Dixit, S. Mishra, and S. Srivastava, "Alcohol detection based engine locking system using MQ-3 sensor," International Research Journal of Engineering and Technology, vol. 4, no. 4, pp. 979-981, 2017.

[12] S. Al-Youif, M. A. M. Ali, and M. N. Mohammed, "Alcohol detection for car locking system," 2018 IEEE Symposium on Computer Applications \& Industrial Electronics (ISCAIE), pp. 230-233, 2018.

[13] Keerthana K., Ramya G., and N. Bharathi, "Drunk driving detection using car ignition locking," International Journal of Pure and Applied Mathematics, vol. 119, no. 16, pp. 2997-3008, 2018.

[14] G. Kavitha, "Driver drowsiness detection and alcoholic alerting system," International Journal of Advanced Research in Computer and Communication Engineering, vol. 5, no. 5, pp. 1029-1031, May 2016.

[15] Zenachew M. and Gebremicheal Te-ame, "Microcontroller based automatic vehicle lock control system of drunken driver," Dissertation, Industrial Control Engineering, Ethiopian Institute of Technology-Mekelle, 2014.

[16] M. S. Kumar and M. K. Kumar, "Automated control system for alcohol and pollution detection in vehicles," International Journal of Scientific Engineering and Technology Research, vol. 3, no. 36, pp. 7172-7175, 2014.

[17] P. Ingalepatil, P. Barhate, B. Nemade, and V. D. Chaudhari, "Alcohol detection system in vehicle using arduino," International Research Journal of Engineering and Technology, vol. 4, no. 06, pp. 287-291, 2017.

[18] D. E. Gbenga, H. I. Hamed, A. A. Lateef, and A. E. Opeyemi, "Alcohol detection of drunk drivers with automatic car engine locking system," Nova Journal of Engineering and Applied Sciences, vol.6, no. 1, pp. 1-15, 2017.

[19] S. Jhunjhunwala, H. Gahlaut, H. R. Singh, R. Daman, and K. Pandey, "Driver soberness system for road vehicles," 2017 International Conference on Computer, Communications and Electronics (Comptelix), pp. 49-52, 2017.

[20] V. N. Kukre, O. Mane, O. Gujar, P. Enpure, and M. Bhise, "Alcohol detection system with vehicle tracking," International Journal of Advance Research and Innovative Ideas in Education, vol. 4, no. 2, pp. 771-774, 2018.

[21] A. Kumar and A. Bansal, "Drink \& drive detection technique with ignition lock," International Journal of Applied Engineering Research, vol. 13, no. 6, pp. 13-16, 2018.

[22] A. K. Patnik, M. KVS Manichandu, J. S. S. Keerthi, G. Satish, and Y. Chanukya., "Drunk and drive detection with ignition lock using raspberry PI," Int. J \& Mag of Eng, Tech, Management and Res, vol. 6, no. 4, pp. 1-4, 2019.

[23] RobotShop, “Arduino Mega 2560 Datasheet," pp.1-7, 2015. [Online]. Available at: https://www.robotshop.com/media/files/pdf/arduinomega2560datasheet.pdf.

[24] Kuongshun, "NEO-6 u-blox 6 GPS Modules," Open Impulse, pp. 1-25, 2017. [Online]. Available at: https://www.openimpulse.com/blog/wp-content/uploads/wpsc/downloadables/GY-NEO6MV2-GPS-Module-Datasheet.pdf.

[25] Research Design Lab,“Gprs/Gsm Sim900a Modem with Arduino Compatible-usermanual,” pp. 1-15, 2014. [Online]. Available at: https://researchdesignlab.com/projects/GPRSGSM\%20SIM900A\%20MODEM\%20with\%20aurdino $\% 20$ compatible.pdf. 